\title{
The FCRL3 -169T>C polymorphism and the risk of endometriosis-related infertility in a Polish population
}

\author{
Malgorzata Szczepańska • Przemyslaw Wirstlein • \\ Hanna Hołysz • Jana Skrzypczak • \\ Paweł P. Jagodziński
}

Received: 19 November 2012 / Accepted: 25 March 2013/Published online: 4 April 2013

(C) The Author(s) 2013. This article is published with open access at Springerlink.com

\begin{abstract}
Objective Recently, the FCRL3 -169T >C (rs7528684) single-nucleotide polymorphism (SNP) has been demonstrated to be a risk factor of endometriosis related infertility. We studied whether the $F C R L-169 \mathrm{~T}>\mathrm{C}$ SNP can be associated with endometriosis-related infertility in a sample of the Polish population

Methods Using PCR-RFLP analysis we genotyped 141 infertile women with endometriosis and 519 fertile women. FCRL3 transcript levels were determined by reverse transcription and real-time quantitative PCR analysis in CD19 ${ }^{+}$ $B$ cells from women with endometriosis-associated infertility and fertile women

Results We found a significantly increased frequency of the FCRL3 C/C genotype in women with endometriosisassociated infertility than controls $[\mathrm{OR}=1.681(95 \%$ $\left.\left.\mathrm{CI}=1.120-2.522, \quad p=0.0116, \quad p_{\text {corr }}=0.0348\right)\right]$. There was also a statistically increased frequency of the $\mathrm{C} / \mathrm{C}$ and $\mathrm{C} / \mathrm{T}$ genotypes in patients compared with controls $[\mathrm{OR}=2.009 \quad(95 \% \quad \mathrm{CI}=1.214-3.324, \quad p=0.0059$, $\left.\left.p_{\text {corr }}=0.0177\right)\right]$. The $p$ value of the $\chi^{2}$ test for the trend
\end{abstract}

\section{Szczepańska · P. Wirstlein · J. Skrzypczak}

Division of Reproduction, Department of Obstetrics,

Gynecology and Gynecological Oncology, Poznań University

of Medical Sciences, Poznań, Poland

P. Wirstlein · P. P. Jagodziński ( $₫)$

Department of Biochemistry and Molecular Biology, Poznań

University of Medical Sciences, 6 Święcickiego St.,

60-781 Poznań, Poland

e-mail: pjagodzi@am.poznan.pl

H. Hołysz

Department of Clinical Chemistry and Molecular Diagnostics, Poznań University of Medical Sciences, 49 Przybyszewskiego St., 60-355 Poznań, Poland observed for the FCRL3 $-169 \mathrm{~T}>\mathrm{C}$ polymorphism was also statistically significant $\left(p_{\text {trend }}=0.0012, p_{\text {corr }}=0.0036\right.$ ). We also found significantly increased FCRL3 transcript levels in carriers of the FCRL3 -169 CC vs TT and CT vs TT genotype both in women with endometriosis-related infertility $(p=0.012 ; p=0.015)$ and fertile women $(p=0.017 ; p=0.032)$

Conclusions FCRL3 $-169 \mathrm{~T}>\mathrm{C}$ polymorphism alters the expression of FCRL3 and can be a risk factor of endometriosis-related infertility.

Keywords Polymorphisms - Endometriosis - Infertility

\section{Introduction}

Endometriosis is a gynecological disorder that develops in approximately $6-10 \%$ of reproductive age women [1]. This disease is attributed to the presence of ectopic endometrial tissue in the abdominal organs and the abdominal cavity [1,2]. Although endometriosis has been intensively studied, the exact cause of this disorder and associated infertility is still unclear [1-3]. Involvement of the genetic background, environmental factors, and changes in the endocrine and immune systems are recognized in the development and persistence of endometriosis [1-3].

The growth of endometrium that implants outside the uterine cavity in women with endometriosis can be explained by two main findings. First, the endometriotic implants display activation of oncogenic pathways or increased activity of estrogen action, as well as prostaglandins, cytokines, and metalloproteinases supporting their survival [4]. Second, the ability of endometrium implants to survive outside the uterus may be linked to a defective immune system that is unable to clear these endometrial implants $[4,5]$. 
It has been demonstrated that reduced natural killer cell cytotoxicity and cytokines biosynthesized by peritoneal macrophages may increase implantation and growth of ectopic endometrial tissue [6-8]. There is also evidence that B lymphocytes play a significant role in the pathogenesis of endometriosis [9]. They produce autoantibodies, which are commonly seen in various autoimmune diseases [9]. This indicates that genetic factors that modulate the function of B cells may be associated with endometriosis and endometriosis-related infertility.

Recently, the FCRL3 gene, encoding Fc receptor-like 3 (FCRL3), was suggested as a novel autoimmune risk factor [10]. FCRL3 is an orphan cell surface receptor presented mainly in B lymphocytes of lymph nodes and germinal centers [11]. The single-nucleotide polymorphism (SNP) $-169 \mathrm{~T}>\mathrm{C}$ (rs7528684), situated in the promoter region, changes the expression of FCRL3 [10]. In addition to this finding, Kochi et al. (2008) demonstrated the FCRL3 169C gene variant effect on the inhibitory potential of $B$ cell receptor-mediated signaling that alters the activation threshold and promotes tolerance breakdown in B cells [11]. Recently, the FCRL3 - 169T >C SNP was demonstrated as a risk factor of endometriosis related infertility [12]. Therefore, we studied whether the FCRL3 -169T $>C$ SNP may be associated with endometriosis-related infertility in a sample of the Polish population.

\section{Materials and methods}

Patients and controls

Peripheral blood samples from women with endometriosis and control women were obtained from the Gynecologic and Obstetrical University Hospital, Division of Reproduction at Poznan University of Medical Sciences. The studied women were allocated into one of two groups: 141 were primary infertility women with endometriosis and

Table 1 Clinical characteristics of women with endometriosis and controls

\begin{tabular}{lll}
\hline Characteristic & Endometriosis & Controls \\
\hline Numbers & 141 & 519 \\
Age (years) & $33(21-38)^{\mathrm{a}}$ & $33(20-39)^{\mathrm{a}}$ \\
Parity & NA & $1(1-4)^{\mathrm{a}}$ \\
Duration of infertility (years) & $4(1-8)^{\mathrm{a}}$ & NA \\
RASRM (stage) & Stage I $(n=69)$ & NA \\
& Stage II $(n=72)$ & \\
\hline
\end{tabular}

NA not applicable

Median ${ }^{\text {a }}$ (Range), revised American Society for Reproductive Medicine classification ${ }^{\mathrm{b}}$ (rASRM) [13]
519 women were used as the fertile controls (Table 1). Inclusion criteria for infertile women with endometriosis were regular menses, no anatomical changes in the reproductive tract, no hormonal treatments, and a minimum of 1 year of infertility with a current desire for conception. Exclusion criteria were male factor infertility, polycystic ovary syndrome (PCOS), mechanical distortion of the endometrial cavity by fibroids, and bilateral tubal occlusion. All included patients with endometriosis had laparoscopic and histological diagnosis of endometriosis. The stage of endometriosis was assessed according to the revised classification of the American Society for Reproductive Medicine (rASPM) [13].

The fertile women assigned to the control group were examined for the cause of chronic pelvic pain without any pelvic abnormalities determined by laparoscopy. The controls were diagnosed as having varicose veins in the pelvic floor but no signs of past or present inflammation. Inclusion criteria for fertile control women were regular menses, no anatomical changes in the reproductive tract, no hormonal treatments, and at least one child born no more than 1 year before laparoscopy (Table 1). Exclusion criteria were diagnosis of past or present inflammation, pelvic abnormalities, endometriotic lesions, PCOS, and bilateral tubal occlusion. All included control women were laparoscopically examined due to chronic pelvic pain and suspected endometriosis, pelvic floor varicose veins. Patients and controls were matched by age and were all Caucasian of Polish descent (Table 1). Written informed consent was obtained from all participating individuals. The study procedures were approved by the Local Ethical Committee of Poznan University of Medical Sciences.

\section{Genotyping}

DNA was isolated from peripheral leucocytes using a standard salting out procedure. Identification of the FCRL3 $-169 \mathrm{~T}>\mathrm{C}$ (rs7528684) polymorphic variant was performed by polymerase chain reaction-restriction fragment length polymorphism (PCR-RFLP). PCR was conducted employing primer pair 5'CTGAACAGGAAAATAATAC AAATGT 3'and 5'TGAAACAAAATAATGGGGTGGAA $3^{\prime}$. The PCR-amplified fragments of FCRL3 that were $167 \mathrm{bp}$ in length were isolated and digested with the endonuclease BsmFI ( $5^{\prime}$ GGGAC $\left.(\mathrm{N})_{10} / 3^{\prime}\right)$ New England BioLabs (Ipswich, USA). The FCRL3 $\mathrm{C}$ allele was cleaved into 119 and 48 bp fragments, whereas the FCRL3 T allele remained uncut. DNA fragments were separated by electrophoresis on $3 \%$ agarose gel and visualized by ethidium bromide staining. The FCRL3 $-169 \mathrm{~T}>\mathrm{C}$ polymorphism was confirmed by repeated PCR-RFLP for all samples. Furthermore, $20 \%$ of randomly selected samples were confirmed by commercial sequencing analysis. 
$\mathrm{CD} 19^{+} \mathrm{B}$ cell isolation

A 5-ml blood sample from women with endometriosis related infertility or controls was collected into tubes containing EDTA. To obtain $\mathrm{CD} 19^{+} \mathrm{B}$ cells from whole peripheral blood, we used the positive biomagnetic separation technique using Dynabeads ${ }^{\circledR}$ CD19 Pan B, Dynal Biotech (Oslo, Norway) according to the manufacturer's instructions. Magnetic beads were detached by DETACHaBEAD ${ }^{\circledR}$ CD19, Dynal Biotech (Oslo, Norway) using a polyclonal sheep anti-mouse-Fab antibody. Isolated $\mathrm{CD} 19^{+}$cells were washed twice at room temperature in modified Eagle's medium, followed by total RNA isolation.

Real-time quantitative PCR (RQ-PCR) analysis of FCRL3 transcript level in CD19 $9^{+} \mathrm{B}$ cells

Total RNA was isolated according to the method of Chomczyński and Sacchi [14]. RNAs samples were treated with DNase I, quantified and reverse-transcribed (RT) into cDNA. Quantitative analysis of FCRL3 cDNA was performed by Light Cycler $^{\circledR} 480$ II Real-Time PCR System, Roche Diagnostics GmbH (Mannheim, Germany), using SYBR Green I as detection dye. FCRL3 cDNA was quantified using the relative quantification method with a calibrator. The calibrator was prepared as a cDNA mix from all cDNA samples and consecutive dilutions were used to create a standard curve as described in Relative Quantification Manual Roche Diagnostics GmbH (Mannheim, Germany). For amplification, $1 \mu \mathrm{l}$ of cDNA solution was added to $9 \mu \mathrm{l}$ of LightCycler 480 SYBR Green I Master Mix Roche Diagnostics GmbH (Mannheim, Germany) and primers. The quantity of FCRL3 transcript in each sample was standardized by the porphobilinogen deaminase (PBGD) transcript level. The PCR amplification efficiency for target and reference genes was determined by different standard curves created by consecutive dilutions of the cDNA template mixture, as provided in Relative Quantification Manual Roche Diagnostics GmbH (Mannheim, Germany). The FCRL3 cDNA 123 bp amplicon was amplified employing the primer pair: (forward $5^{\prime}$ GGTCACAGTTCCGGTGTCTC $3^{\prime}$ ) and (reverse $5^{\prime}$ CAG TACAGGATCGGGAAGGA3'). The PBGD cDNA 160 bp amplicon was amplified using the primer pair: (forward $5^{\prime}$ GCC AAG GAC CAG GAC ATC 3') (reverse 5' TCA GGT ACA GTT GCC CAT C $3^{\prime}$ ). The FCRL3 mRNA levels were expressed as multiples of these cDNA concentrations in the calibrator.

\section{Statistical analysis}

The distribution of genotypes in patients and controls was examined for deviation from Hardy-Weinberg equilibrium.
Since the best inheritance model contribution of FCRL3 $169 \mathrm{~T}>\mathrm{C}$ SNP to endometriosis-related infertility is unknown in our population, the data were analyzed under recessive and dominant models. In addition, to determine the polymorphism's association with endometriosis-related infertility, the additive genetic model was tested using Armitage's test for trend $\left(p_{\text {trend }}\right)$. The differences in genotype frequencies between cases and controls were determined using standard Chi squared $\left(\chi^{2}\right)$, the Odds ratio (OR), and $95 \%$ Confidence intervals $(95 \% \mathrm{CI})$ were calculated and a $p$ value $<0.05$ was considered statistically significant. Power calculations for this study were conducted using Quanto software (Gauderman WJ, Morrison JM. QUANTO 1.2: A computer program for power and sample size calculations for genetic-epidemiology studies, URL: http://hydra.usc.edu/gxe, 2006). Statistical analysis of FCRL3 transcript level comparison between CC vs TT and CT vs TT genotype carriers was evaluated by Mann-Whitney Rank Sum Test.

\section{Results}

Distribution of the FCRL3 - 169T $>$ C polymorphism in women with endometriosis associated infertility

Genotype evaluation of the FCRL3 $-169 \mathrm{~T}>\mathrm{C}$ polymorphism did not demonstrate significant aberration from the Hardy-Weinberg equilibrium in the patient and control groups.

We found an approximately 1.4-fold significantly increased frequency of the FCRL3 $\mathrm{C} / \mathrm{C}$ genotype in in women with infertility-associated endometriosis over the controls $[\mathrm{OR}=1.681 \quad(95 \% \quad \mathrm{CI}=1.120-2.522$, $\left.\left.p=0.0116, p_{\text {corr }}=0.0348\right)\right]$. There was also a significantly increased frequency of the $\mathrm{C} / \mathrm{C}$ and $\mathrm{C} / \mathrm{T}$ genotypes in patients compared with controls $[\mathrm{OR}=2.009(95 \%$ $\left.\left.\mathrm{CI}=1.214-3.324, p=0.0059, p_{\text {corr }}=0.0177\right)\right]($ Table 2$)$. The $p$ value of the $\chi^{2}$ test for the trend observed for the FCRL3 - 169T $>$ C polymorphism was also statistically significant $\left(p_{\text {trend }}=0.0012, p_{\text {corr }}=0.0036\right)$.

A power analysis predicted sufficient power to detect an association of the FCRL3 $-169 \mathrm{~T}>\mathrm{C}$ polymorphism with a genetic effect of 2.00 or more for the dominative model and a genetic effect of 1.80 or more for the recessive model (Table 3).

Effect of FCRL3 - 169T $>$ C polymorphism on FCRL3 transcript levels in $\mathrm{CD} 19^{+} \mathrm{B}$ cells from fertile women and women with endometriosis-related infertility

We observed significantly increased FCRL3 transcript levels in the $\mathrm{CD} 19^{+} \mathrm{B}$ cells from carriers of the FCRL3 $-169 \mathrm{C}$ gene variant as compared with carriers of the FCRL3 -169 
Table 2 Association of the FCRL3 -169T >C (rs7528684) SNP with endometriosis-related infertility

\begin{tabular}{|c|c|c|c|c|c|c|c|c|}
\hline \multirow[t]{2}{*}{ Gene (rs no.) } & \multirow[t]{2}{*}{ Alleles ${ }^{\mathrm{a}}$} & \multirow[t]{2}{*}{$\mathrm{MAF}^{\mathrm{b}}$} & \multicolumn{3}{|c|}{ Genotypes $^{\mathrm{c}}$} & \multirow{2}{*}{$\begin{array}{l}\mathrm{OR}_{\text {recessive }}(95 \% \mathrm{CI}) \\
p \text { value }^{\mathrm{d}}\end{array}$} & \multirow{2}{*}{$\begin{array}{l}\mathrm{OR}_{\text {dominant }}(95 \% \mathrm{CI}) \\
p \text { value }^{\mathrm{d}}\end{array}$} & \multirow{2}{*}{$\begin{array}{l}p_{\text {trend }} \\
\text { value }^{\mathrm{e}}\end{array}$} \\
\hline & & & Cas & & Controls & & & \\
\hline \multirow[t]{2}{*}{ FCRL3 (rs7528684) } & $\mathrm{c} / \mathrm{T}$ & 0.49 & no & $21 / 73 / 47$ & $135 / 265 / 119$ & $1.681(1.120-2.522) ; 0.0116$ & 2.009 (1.214-3.324); 0.0059 & 0.0012 \\
\hline & & & $\%$ & $15,52,33$ & $26,51,23$ & & & \\
\hline
\end{tabular}

${ }^{a}$ Uppercase denotes the more frequent allele in the control samples

b MAF, minor allele frequency calculated from the control samples

c The order of genotypes: DD/Dd/dd ( $\mathrm{d}$ is the minor allele)

d Chi square analysis

e Cochran-Armitage trend test

Table 3 Power analysis

\begin{tabular}{lll}
\hline & \multicolumn{2}{l}{ Model } \\
\cline { 2 - 3 } Genetic effect & Dominant & Recessive \\
\hline 1.00 & 0.0500 & 0.0500 \\
1.20 & 0.1300 & 0.1342 \\
1.40 & 0.3153 & 0.3532 \\
1.60 & 0.5239 & 0.6119 \\
1.80 & 0.6967 & 0.8106 \\
2.00 & 0.8169 & 0.9224 \\
2.20 & 0.8925 & 0.9723 \\
\hline
\end{tabular}

Power calculations for this study were conducted using Quanto software (Gauderman WJ, Morrison JM. QUANTO 1.2: A computer program for power and sample size calculations for genetic-epidemiology studies, URL: http://hydra.usc.edu/gxe, 2006). Power analysis was conducted with the following parameters: allele frequency 0.49 , frequency of endometriosis associated infertility 0.03 in population, significance level 0.05, two-sided

TT genotype in fertile women. The median of FCRL3 transcript levels in B cells from fertile women with the CC genotype was 1.263 (range $0.305-0.421$ ) ( $p=0.017$ ), 1.060 (range 0.430-2.899) ( $p=0.032)$ for the CT genotype, and 0.663 (range 0.301-1.349) for the TT genotype (Fig. 1a). There were also significantly increased FCRL3 transcript levels in the $\mathrm{CD} 19^{+} \mathrm{B}$ cells from carriers of the FCRL3 - 169 C gene variant as compared with carriers of the FCRL3 - 169 TT genotype in women with endometriosis-related infertility. The median of FCRL3 transcript levels in B cells from endometriosis women with the CC genotype was 1.017 (range 0.493-2.120) ( $p=0.012)$, with the CT genotype was 0.951 (range 0.406-2.616) $(p=0.015)$, and with the TT genotype was 0.485 (range $0.391-0.611$ ) (Fig. 1b).

\section{Discussion}

Endometriosis is a complex disease accompanied by changes in the expression of genes encoding proteins affecting sex hormone activity, proteins involved in vascular and tissue rebuilding, glucose homeostasis enzymes, and inflammatory mediators [15]. Infertility is recognized in 30 to $50 \%$ of women with endometriosis [1-3]. This disorder disturbs most stages of reproduction, including granulosa cell steroidogenesis, folliculogenesis, ovulation, fertilization, and blastocyst implantation [1, 16, 17].

There are several pieces of evidence that demonstrate the involvement of an abnormal humoral immune response in the infertility of women with endometriosis. In patients with endometriosis, B cells have been shown to produce autoantibodies recognizing phospholipids, histones, polynucleotides, and even autoantibodies characteristic for lupus [18, 19]. The presence in blood plasma of autoantibodies against endometrial, ovarian, and laminin-1 tissues may partially explain subfertility in women with endometriosis [20, 21]. Moreover, women with endometriosis exhibit headaches, arthralgia, myalgia, fibromyalgia, chronic fatigue syndrome, and other symptoms characteristic for patients with autoimmune disease [22-24]. This suggests common candidate genes that contribute to the pathogenesis of autoimmunity and endometriosis [25].

We observed an association of the FCRL3 - 169T $>\mathrm{C}$ polymorphism with occurrence of endometriosis related infertility. To date, the rs7528684 SNP has been recognized as a genetic risk factor of endometriosis-related infertility as well as idiopathic infertility in Brazilian women [12, 26, 27].

The FCRL3 - 169T $>$ C polymorphism has also been identified as a risk factor of various autoimmune diseases, including rheumatoid arthritis, systemic lupus erythematosus, Hashimoto thyroiditis, Graves' disease, and biliary cirrhosis [10, 28].

We also found significantly increased FCRL3 transcript levels in the $\mathrm{CD}_{19}{ }^{+} \mathrm{B}$ cells from carriers of the FCRL3 $-169 \mathrm{~T} \mathrm{C}$ gene variant as compared with carriers of the FCRL3 -169 TT genotype both in women with endometriosis-related infertility and fertile women. To date, it has 

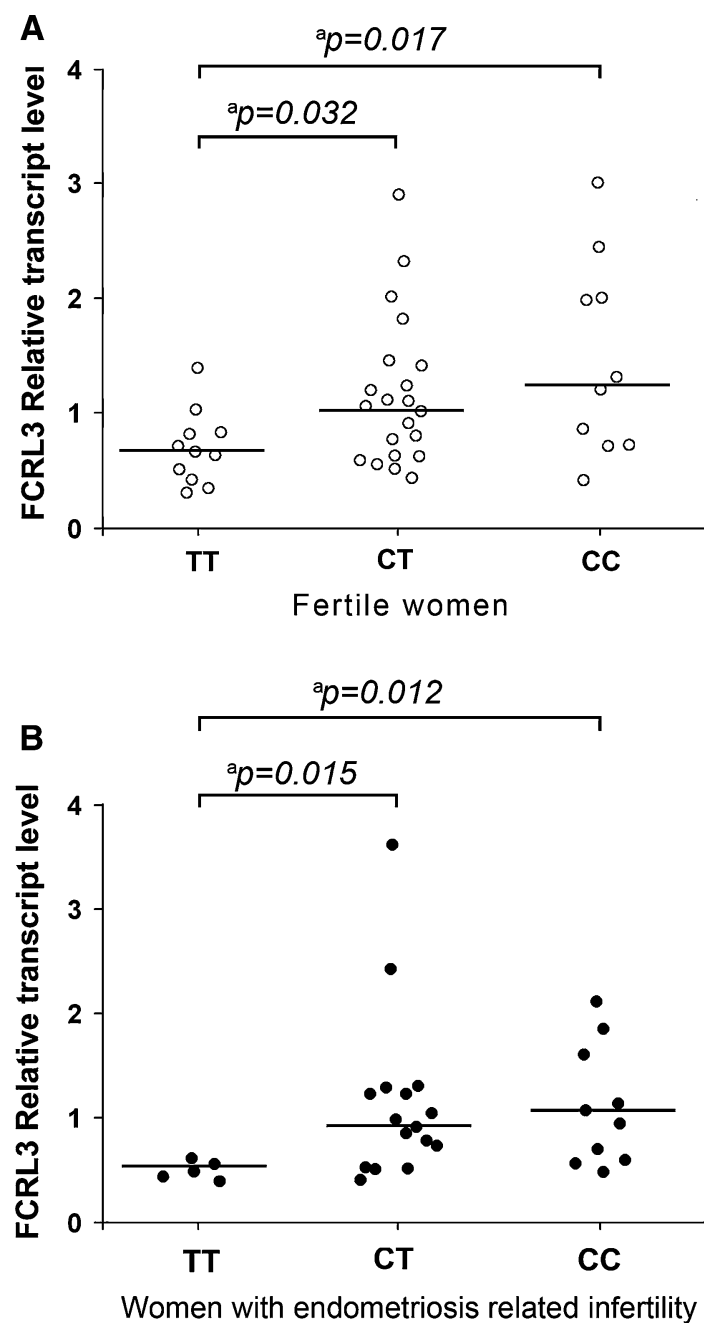

Fig. 1 Effect of the FCRL3 -169T $>$ C polymorphism on FCRL3 transcript levels in $\mathrm{CD} 19^{+} \mathrm{B}$ cells in fertile women (a) and in women with endometriosis related infertility (b). The CD19 ${ }^{+} \mathrm{B}$ cells from whole venous peripheral blood were isolated using positive biomagnetic separation technique. Quantitative analyses of FCRL3 transcript levels were performed by RT and RQ-PCR SYBR Green I system. The open circles correspond to transcript levels in fertile women, carriers of CC, CT, and TT genotypes. The black circles represent FCRL3 transcript levels in $\mathrm{CD} 19^{+} \mathrm{B}$ cells from women with endometriosis-associated infertility, carriers of CC, CT, and TT genotypes. ${ }^{\mathrm{a}}$ Mann-Whitney Rank Sum Test

been observed that the $F C R L 3-169 \mathrm{~T}>\mathrm{C}$ SNP affects the expression of FCRL3 by changing the affinity binding of nuclear factor-kappa B (NF- $\mathrm{KB})$ to its promoter. Kochi et al. [10], using luciferase reporter gene analysis, demonstrated the significantly increased transcriptional activity of the disease-susceptible FCRL3 $-169 \mathrm{C}$ gene variant as compared with the non-disease-susceptible FCRL3 - 169T gene variant. Moreover, Gibson et al. [29] demonstrated that venous blood $\mathrm{CD} 19^{+} \mathrm{B}$ cells from normal donors, $-169 \mathrm{CC}$ homozygotes, exhibited significantly higher levels of the FCRL3 protein than B cells from TT homozygotes.
To date, the genetic risk factors for endometriosis-related infertility have included the $17 \beta$-hydroxysteroid dehydrogenase type 1, ESR1, ESR2, and luteinizing hormone beta-subunit genes [30-33]. Furthermore, polymorphisms situated in FOXP, complement component 3, and lysyl oxidase-like protein 4 genes have also been reported as genetic factors which affect fertility in women with endometriosis [27, 34].

Our study confirmed an association of the FCRL3 $-169 \mathrm{~T}>\mathrm{C}$ polymorphism with endometriosis-related infertility. Our genetic studies were conducted on a limited number of infertile women with endometriosis; therefore, the role of this polymorphism should be further studied in women with idiopathic infertility and a larger and independent cohort of women with endometriosis-related infertility.

Acknowledgments Supported by Grant No 502-01-0112418207474 and 502-01-01110142-00304, Poznan University of Medical Sciences.

Conflict of interest We declare that we have no conflict of interest.

Open Access This article is distributed under the terms of the Creative Commons Attribution License which permits any use, distribution, and reproduction in any medium, provided the original author(s) and the source are credited.

\section{References}

1. de Ziegler D, Borghese B, Chapron C (2010) Endometriosis and infertility: pathophysiology and management. Lancet 376: 730-738

2. Ulukus M, Cakmak H, Arici A (2006) The role of endometrium in endometriosis. J Soc Gynecol Investig 13:467-476

3. Brosens I, Benagiano G (2011) Endometriosis, a modern syndrome. Indian J Med Res 133:581-593

4. Bulun SE (2009) Endometriosis. N Engl J Med 360:268-279

5. Berbic M, Fraser IS (2011) Regulatory T cells and other leukocytes in the pathogenesis of endometriosis. J Reprod Immunol 88:149-155

6. Matarese G, De Placido G, Nikas Y, Alviggi C (2003) Pathogenesis of endometriosis: natural immunity dysfunction or autoimmune disease? Trends Mol Med 9:223-228

7. Sikora J, Mielczarek-Palacz A, Kondera-Anasz Z (2011) Role of natural killer cell activity in the pathogenesis of endometriosis. Curr Med Chem 18:200-208

8. Berkkanoglu M, Arici A (2003) Immunology and endometriosis. Am J Reprod Immunol 50:48-59

9. Carp HJ, Selmi C, Shoenfeld Y (2012) The autoimmune bases of infertility and pregnancy loss. J Autoimmun 38:J266-J274

10. Kochi Y, Yamada R, Suzuki A, Harley JB, Shirasawa S, Sawada T, Bae SC, Tokuhiro S, Chang X, Sekine A, Takahashi A, Tsunoda T, Ohnishi Y, Kaufman KM, Kang CP, Kang C, Otsubo S, Yumura W, Mimori A, Koike T, Nakamura Y, Sasazuki T, Yamamoto K (2005) A functional variant in FCRL3, encoding Fc receptor-like 3, is associated with rheumatoid arthritis and several autoimmunities. Nat Genet 37:478-485

11. Kochi Y, Myouzen K, Yamada R, Suzuki A, Kurosaki T, Nakamura Y, Yamamoto K (2009) FCRL3, an autoimmune 
susceptibility gene, has inhibitory potential on B-cell receptormediated signaling. J Immunol 183:5502-5510

12. Teles JS, Bianco B, Vilarino FL, André GM, Christofolini DM, Barbosa CP (2011) Association of FCRL3 C-169T promoter single-nucleotide polymorphism with idiopathic infertility and infertility-related endometriosis. J Reprod Immunol 89:212-215

13. Canis M, Donnez JG, Guzick DS, Halme JK, Rock JA, Schenken RS (1997) Vernon MW Revised American Society for Reproductive Medicine classification of endometriosis: 1996. Fertil Steril 67:817-821

14. Chomczynski P, Sacchi N (1987) Single-step method of RNA isolation by acid guanidinium thiocyanate-phenol-chloroform extraction. Anal Biochem 162:156-159

15. Montgomery GW, Nyholt DR, Zhao ZZ, Treloar SA, Painter JN, Missmer SA, Kennedy SH, Zondervan KT (2008) The search for genes contributing to endometriosis risk. Hum Reprod Updat $14: 447-457$

16. Simón C, Gutiérrez A, Vidal A, de los Santos MJ, Tarín JJ, Remohí J, Pellicer A (1994) Outcome of patients with endometriosis in assisted reproduction: results from in vitro fertilization and oocyte donation. Hum Reprod 9:725-729

17. Tummon IS, Maclin VM, Radwanska E, Binor Z, Dmowski WP (1988) Occult ovulatory dysfunction in women with minimal endometriosis or unexplained infertility. Fertil Steril 50:716-720

18. Taylor PV, Maloney MD, Campbell JM, Skerrow SM, Nip MM, Parmar R, Tate G (1991) Autoreactivity in women with endometriosis. Br J Obstet Gynaecol 98:680-684

19. Lebovic DI, Mueller MD, Taylor RN (2001) Immunobiology of endometriosis. Fertil Steril 75:1-10

20. Dmowski WP, Rana N, Michalowska J, Friberg J, Papierniak C, el-Roeiy A (1995) The effect of endometriosis, its stage and activity, and of autoantibodies on in vitro fertilization and embryo transfer success rates. Fertil Steril 63:555-562

21. Inagaki J, Sugiura-Ogasawara M, Nomizu M, Nakatsuka M, Ikuta K, Suzuki N, Kaihara K, Kobayashi K, Yasuda T, Shoenfeld Y, Aoki K, Matsuura E (2003) An association of IgG anti-laminin-1 autoantibodies with endometriosis in infertile patients. Hum Reprod 18:544-549

22. Tietjen GE, Bushnell CD, Herial NA, Utley C, White L, Hafeez F (2007) Endometriosis is associated with prevalence of comorbid conditions in migraine. Headache 47:1069-1078

23. Pasoto SG, Abrao MS, Viana VS, Bueno C, Leon EP, Bonfa E (2005) Endometriosis and systemic lupus erythematosus: a comparative evaluation of clinical manifestations and serological autoimmune phenomena. Am J Reprod Immunol 53:85-93

24. Sinaii N, Cleary SD, Ballweg ML, Nieman LK, Stratton P (2002) High rates of autoimmune and endocrine disorders, fibromyalgia, chronic fatigue syndrome and atopic diseases among women with endometriosis: a survey analysis. Hum Reprod 17:2715-2724

25. Bianco B, André GM, Vilarino FL, Peluso C, Mafra FA, Christofolini DM, Barbosa CP (2012) The possible role of genetic variants in autoimmune-related genes in the development of endometriosis. Hum Immunol 73:306-315

26. Bianco B, Teles JS, Lerner TG, Vilarino FL, Christofolini DM, Barbosa CP (2011) Association of FCRL3 - 169T/C polymorphism with endometriosis and identification of a protective haplotype against the development of the disease in Brazilian population. Hum Immunol 72:774-778

27. Barbosa CP, Teles JS, Lerner TG, Peluso C, Mafra FA, Vilarino FL, Christofolini DM, Bianco B (2012) Genetic association study of polymorphisms FOXP3 and FCRL3 in women with endometriosis. Fertil Steril 97:1124-1128

28. Tanaka A, Ohira H, Kikuchi K, Nezu S, Shibuya A, Bianchi I, Podda M, Invernizzi P, Takikawa H (2011) Genetic association of Fc receptor-like 3 polymorphisms with susceptibility to primary biliary cirrhosis: ethnic comparative study in Japanese and Italian patients. Tissue Antigens 77:239-243

29. Gibson AW, Li FJ, Wu J, Edberg JC, Su K, Cafardi J, Wiener H, Tiwari H, Kimberly RP, Davis RS (2009) The FCRL3-169CT promoter single-nucleotide polymorphism, which is associated with systemic lupus erythematosus in a Japanese population, predicts expression of receptor protein on CD19+ B cells. Arthr Rheum 60:3510-3512

30. Lamp M, Peters M, Reinmaa E, Haller-Kikkatalo K, Kaart T, Kadastik U, Karro H, Metspalu A, Salumets A (2011) Polymorphisms in ESR1, ESR2 and HSD17B1 genes are associated with fertility status in endometriosis. Gynecol Endocrinol 27:425-433

31. Liao WX, Roy AC, Chan C, Arulkumaran S, Ratnam SS (1998) A new molecular variant of luteinizing hormone associated with female infertility. Fertil Steril 69:102-106

32. Mafra FA, Bianco B, Christofolini DM, Souza AM, Zulli K, Barbosa CP (2010) Luteinizing hormone beta-subunit gene (LHbeta) polymorphism in infertility and endometriosis-associated infertility. Eur J Obstet Gynecol Reprod Biol 151:66-69

33. Zulli K, Bianco B, Mafra FA, Teles JS, Christofolini DM, Barbosa CP (2010) Polymorphism of the estrogen receptor $\beta$ gene is related to infertility and infertility-associated endometriosis. Arq Bras Endocrinol Metabol 54:567-571

34. Ruiz LA, Dutil J, Ruiz A, Fourquet J, Abac S, Laboy J, Flores I (2011) Single-nucleotide polymorphisms in the lysyl oxidase-like protein 4 and complement component 3 genes are associated with increased risk for endometriosis and endometriosis-associated infertility. Fertil Steril 96:512-515 